\title{
Infection prevention and control strategies against COVID-19 in Obstetrics department
}

Xiaomei Peng ${ }^{1}$, Chao $\mathrm{LI}^{2}$, and Xiaolan $\mathrm{Wu}^{2}$

${ }^{1}$ The 5th Poeple's Hospital of Chengdu

${ }^{2}$ Affiliation not available

May 12, 2020

\section{Hosted file}

\begin\{CJK\}\{UTF8\}\{gbsn\}. \end\{CJK\}\selectlanguage\{english\}doc available at https://authorea. } com/users/320953/articles/450344-infection-prevention-and-control-strategies-againstcovid-19-in-obstetrics-department

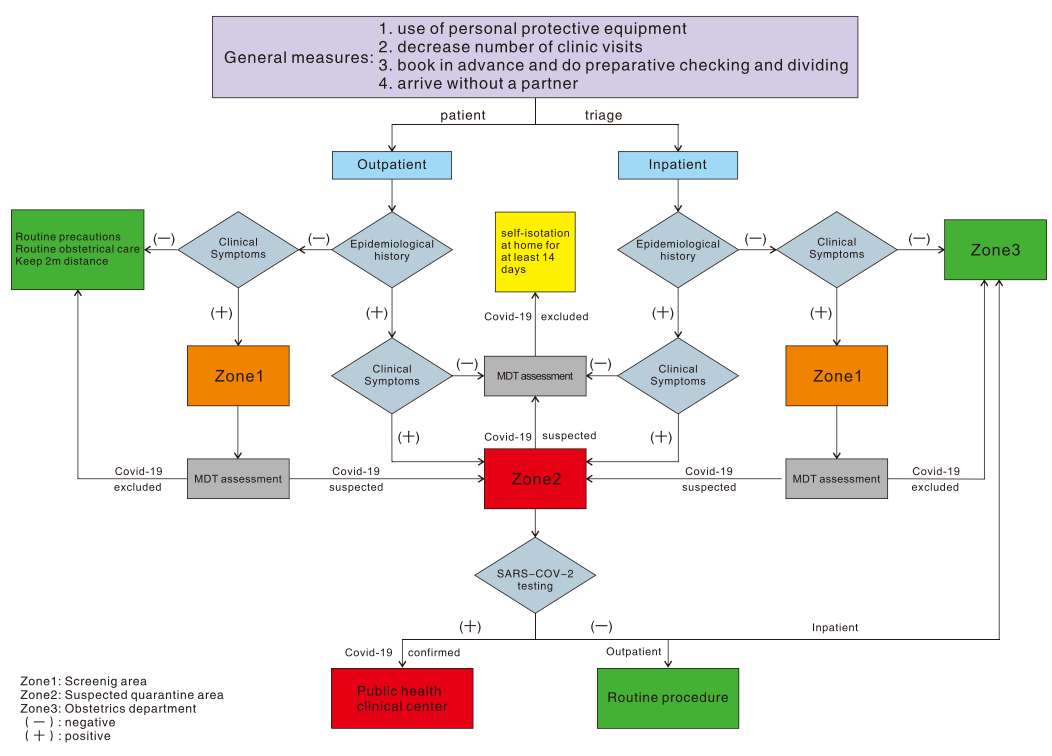

